\title{
STRANGE PARTS: THE METAPHYSICS OF NON-CLASSICAL MEREOLOGIES
}

\author{
A. J. Cotnoir
}

\section{INTRODUCTION}

The smallest bits of matter - the bosons and fermions of microphysics - are parts of larger material objects - the wholes of our everyday macrophysical experience. The formal study of this relation is called mereology. But the notion of parthood is notoriously puzzling. ${ }^{1}$ Witness van Inwagen,
All, or almost all, of the antinomies and paradoxes that the philosophical study of material objects is heir to involve the notion of parthood ...[M]ost of the great, intractable metaphysical puzzles about material objects could be seen to have quite obvious solutions by one who had a clear understanding of what it was for one material object to be a part of another. ((1987), p. 21)

Yet despite the twenty-five years of research into parthood since van Inwagen wrote these words, no clear and complete theory of the nature of the parthood relation has emerged. ${ }^{2}$ In fact, as we shall see, there is no clear consensus on what constitutes a minimal concept

\footnotetext{
${ }^{1}$ For an introduction to some of the traditional philosophical issues surrounding mereology, see McDaniel (2010).

${ }^{2}$ The study of parthood has a long and illustrious history spanning nearly the entire history of Western philosophy. For a thorough history, see Burkhart and Dufour (1991). Our focus here will be on the recent developments in the literature.
} 
of the parthood relation - there is even significant disagreement over which principles of parthood are analytic. The theory of parthood that has achieved the most widespread approval in contemporary metaphysics is classical extensional mereology (CEM) first introduced in Łesniewski(1916), and developed by Tarski (1929), and Leonard \& Goodman (1940). ${ }^{3}$ And yet the controversy over classical extensional mereology rages on.

One main strand of controversy will be the topic of this essay: the connections between parthood and identity. (We will not be focussing on the famous debates over 'Unrestricted Fusion; ${ }^{4}$ nor will we discuss the debate over the transitivity of parthood. ${ }^{5}$. So much of our discussion will extend to what Simons Simons (1987) calls Minimal Extensional Mereology.) According to CEM, parthood is intimately interwoven with identity, such that facts about parthood often entail facts about identity. And as is well-known, facts about identity have wide-ranging consequences for ontology and modality. As a result, a theory of parthood can have important influence over our theories of what there is, and additionally on theories about what there could and couldn't be.

Three main properties of mereological relations come into focus: (i) extensionality, (ii) antisymmetry, and (iii) idempotency.

Extensionality If $x$ and $y$ have the same mereological make-up, then $x$ and $y$ are identical.

Antisymmetry If $x$ is part of $y$ and $y$ part of $x$, then $x$ and $y$ are identical.

Idempotency If $x$ is part of $y$, then the sum of $x$ and $y$ is identical to $y$.

\footnotetext{
${ }^{3}$ In what follows, I presuppose a basic familiarity with mereological concepts. For more formal details should consult Varzi's excellent entry (2006a). Hovda (2009), Pontow and Schubert (2006) give somewhat more advanced analysis of CEM. The reader with formal training would do well to consult Niebergall's excellent (2011).

${ }^{4}$ See McDaniel (2010), §4 for discussion of this issue.

${ }^{5}$ But see Varzi (2006b) for references.
} 
Extensionality actually comprises a class of principles corresponding to different ways of characterizing mereologically indiscernibility, to be explained in detail below. Whether these properties are commitments of CEM is not in question; they are all either theorems or axioms of CEM. What is controversial is whether they are true. A battery of alleged counterexamples to these principles have been put forward. Among those who accept that CEM is problematic, there is still further disagreement over how and why these principles can fail. A number of recent authors have proposed new weaker non-classical mereologies as a remedy. ${ }^{6}$

This article gives a sampling of some of the alleged counterexamples to each of the three principles. Along the way, some of the main revisionary approaches are reviewed. In $\S 2$, we look at counterexamples to extensionality. The 'supplementation' axioms that generate extensionality are examined more carefully, and a suggested revision is considered. §3 considers an alternative approach that focuses the blame on antisymmetry, but allows us to keep natural supplementation axioms. In $\S 4$, we look at counterexamples to the idempotency of composition, and the associated 'parts just once' principle. We explore options for developing weaker mereologies that avoid such commitments.

\section{SUPPLEMENTATION PRINCIPLES \& EXTENSIONALITY}

Extensionality in mereology - same structure, same thing - is so called because of its parallel with the extensionality of sets - same members, same set. Historically, a nominalistically acceptable alternative to set-theory was one of the original motivations for the

\footnotetext{
${ }^{6}$ Non-classical mereology' is a bit of a misnomer, unfortunately. It could easily be confused with mereology based in a non-classical logic. There are some mereological theories based in non-classical logics, e.g. the freelogic mereology of Simons (1991), the fuzzy-logic mereology of N. J. J. Smith (2005), and the paraconsistentlogic mereology of Weber and Cotnoir (n.d.). However, all the mereologies discussed below will be based in classical logic; they are called 'non-classical' because they are weaker than CEM.
} 
development of mereology.

But is extensionality for objects on a par with extensionality for sets? In particular, extensionality and the Indiscernibility of Identicals together give us the following very strong claim: if objects are mereologically indiscernible, then they are indiscernible tout court. But why should mereological structure be so important? Is it true that 'a whole is nothing over and above its parts" ? Or is it rather that 'a whole is greater than the sum of its parts'? Which view is right? The debate over extensionality runs deep.

The classic counterexample to extensionality involves objects (e.g. a statue) and the matter which constitutes them (e.g. a lump of clay). They presumably have different properties: e.g. the clay can survive squashing whereas the statue cannot. They must, therefore, be different objects. Yet every part of one appears to be part of the other. Their structure (insofar as mereology is concerned, anyway) is exactly the same. ${ }^{8}$

Another example involves the construction of two objects by a rearrangement of the same parts. Suppose my son builds a house out of a some lego bricks. He then destroys the house (as he often does), and proceeds to build a boat from the same lego bricks. Is the house identical to the boat? Or are they distinct? ${ }^{9}$ Extensionality would seem to force us to identify the two. ${ }^{10}$

Until now, I have been talking about extensionality in a general way, leaving the notion

\footnotetext{
'It was one of Leśniewski's (1916) explicit motivations, as it was for R. Eberle (1970). Goodman's nominalism, however, appears not to have been a motive for the development of the system of Leonard and Goodman (1940). This system includes explicit set variables which were removed only later in Goodman (1951). See Rossberg (2009).

${ }^{8}$ This is one of the Paradoxes of Material Constitution, popularized by Wiggins (1968). See Paul (2010) for a good introduction and references.

${ }^{9}$ Thomson's (1983) example involves Tinkertoys.

${ }^{10}$ Of course, a temporal parts view a là Sider (2003) would accept extensionality but might reject the identification. Alternatively, one might think that objects such as the lego house have additional non-material (formal?) parts. Representatives of this view are Fine (1999, 2003), Paul (2006), Johnston (2006), and Koslicki (2008). The best-developed formal mereology is Fine (2010).
} 
of mereological structure imprecise. But, the exact formulation of extensionality matters here. CEM includes the following three variants: ${ }^{11}$

Extensionality of Proper Parts If $x$ and $y$ are composite objects with the same proper parts, then $x$ and $y$ are identical.

Extensionality of Overlap If $x$ and $y$ overlap all the same things, then $x$ and $y$ are identical.

Extensionality of Sums If $x$ and $y$ are sums of the same things, then $x$ and $y$ are identical.

Notice that the antecedent of the extensionality of proper parts presumes that the relevant objects are composite. So, CEM allows that two simples (i.e. objects with no proper parts) might trivially have the same proper parts, but still be non-identical. And so one might think that since quantum particles are simples, this gives us a way out. However, it is not only quantum particles that can be entangled, but larger composite objects too. So something has to give.

In his classic book Parts (1987), Simons surveys a range of non-extensional mereologies resulting from dropping so-called 'supplementation principles'. The key candidate is SSP.

Strong Supplementation (SSP) If $y$ is not part of $x$, then there's some $z$ that's part of $y$ but disjoint from $x$

SSP says, roughly, that if something isn't a part of another, then they don't have all the same parts. So long as parthood is a partial order (i.e. reflexive, transitive, and antisymmetric), then SSP implies the extensionality principles above. ${ }^{12}$ Simons recommends dropping SSP

${ }^{12}$ The easiest to see is Extensionality of Overlap. The contrapositive of SSP is: for all $x, y$, and $z$, if $z$ 's being a part of $y$ implies that $z$ overlaps $x$, then $y$ is part of $x$. Weakening the antecedent gives: (a) for all $x, y$, and $z$, if $z$ overlapping $y$ implies that $z$ overlaps $x$, then $y$ is part of $x$. Substituting $x$ for $y$ and $y$ for $x$, we also have: (b) if $z$ overlapping $x$ implies that $z$ overlaps $y$, then $x$ is part of $y$. Putting (a) and (b) together, yields: for all $x, y$, and $z, z$ overlaps $y$ iff $z$ overlaps $x$, only if $x$ and $y$ are parts of each other. Applying antisymmetry to the consequent gives the identity of $x$ and $y$.
} 
in order to avoid puzzles like the examples above. ${ }^{13}$ This allows the mereologist to avoid extensionality ...or so it might seem.

Varzi (2009) has recently argued that rejecting SSP is not sufficient to avoid extensionality principles. A weaker principle, WSP does the trick.

Weak Supplementation (WSP) If $x$ is a proper part of $y$, then there's some $z$ that's part of $y$ but disjoint from $x$.

WSP says that if an object has a proper part, then it must have another part that doesn't overlap with the first. The argument from here to extensionality is too involved to present now, and involves the commitment to mereological universalism - for any things, there is a whole made of them. ${ }^{14}$ But to see the gist, imagine a statue and its clay are distinct objects with the same proper parts. Universalism implies that there must be a sum of the statue and the clay (and moreover, that sum must be distinct from either of them, since neither is part of the other). Now, the statue is a proper part of the sum; however, there is no part of the sum that is disjoint from the statue, as any part of the clay is also part of the statue. This violates WSP.

Many philosophers (including Varzi and Simons) think that WSP is analytic, that it is partly constitutive of the notion of proper parthood. ${ }^{15}$ Accordingly, structures violating WSP are inconceivable. If so, then it would appear that universalism entails extensionalism; anyone who denied extensionality but accepted universalism would be guilty of conceptual confusion.

\footnotetext{
${ }^{13}$ See (1987) \$3.2.4 and chs. 5 and 6. More precisely, he advocates doing so on the basis of what he calls 'The Flux Argument', which is based on a version of the 'Tibbles the cat' thought experiment of Geach (1962).

${ }^{14}$ Actually, it involves a very specific version of universalism involving a particular form of the unrestricted fusion axiom schema. Other variants are not sufficient to generate extensionality. It also rests on a particular definition of proper parthood. See Rea (2010) for a reply. Simons does not accept Universalism, so for him, the rejection of SSP is sufficient.

${ }^{15}$ Varzi says this in several places: (2008) (p. 110) and (2009) (p. 60). Simons (1987) (p. 116) also makes this claim, as do Bohn (2009) (p. 27, footnote 3), Koslicki (2008) (p. 167f), and McDaniel (2009) (p. 264).
} 
Now, claims to analyticity are often regarded with scepticism. True to form, a growing number of metaphysicians endorse a mereology without WSP. ${ }^{16}$ We will consider a few more purported counterexamples in §4; but clearly, something about the spirit of WSP seems right. How could an object that has a proper part fail to have a remainder when that part is removed?

Gilmore (forthcomingb) has recently put forward a supplementation-like principle that is weaker than WSP, but which he thinks captures its intuitive pull.

Quasi-Supplementation (QSP) If $x$ is a proper part of $y$, then there's some $w$ and some $z$ such that both $w$ and $z$ are parts of $y$, and disjoint from each other.

QSP says that if an object has a proper part, then that object must have two proper parts disjoint from each other. Unlike WSP, however, the universalist can accept QSP while avoid extensionality. Returning to our earlier case, the statue is a proper part of the sum, and yet there may well be two parts of the sum that are disjoint from each other (e.g. the top half and the bottom half).

On the other hand, I suggest it is not obvious at all that QSP really does express the intuitive pull behind supplementation. After all, it is compatible with QSP for an object to have only one immediate proper part, so long as it has two disjoint proper parts somewhere down the line. Allow me to explain: imagine you had two particles $a$ and $b$, and their sum $s_{0}$. Suppose further that $s_{0}$ was the only proper part of some other object $s_{1}$, which was the only proper part of some further object $s_{2}$, which in turn was the only proper part of $s_{3}$, and so

\footnotetext{
${ }^{16}$ Caplan, Tillman, and Reader (2010) express sympathy toward the rejection of WSP. Cotnoir and Bacon (2012) argue that WSP is inconsistent with the possibility of parthood loops. Forrest (2002) argues against WSP on the basis of the possibility of gunk and considerations from measure theory (but see Russell(2008)). Smith (2009) provides a number of arguments against WSP from more general metaphysical considerations, as does Donnelly (2011). Donnelly (2010) also rejects WSP on the basis of considerations involving multilocation, as does Kleinschmidt (2011).
} 
on. This structure is compatible with QSP. Now, a natural question to ask is this: what is left of $s_{3}$ when $s_{2}$ is removed? Where is the remainder? This sort of example seems more akin to set-theoretical structures - where $\{\{\{a, b\}\}\}$ is clearly a different set than $\{\{a, b\}\}-$ than it does to mereological structures. ${ }^{17}$

But perhaps such strange parthood structures are part and parcel of tweaking supplementation to avoid extensionality.

\section{THE PROPER PARTS PRINCIPLE \& ANTISYMMETRY}

One need not tweak supplementation principles, however, to obtain non-extensional mereologies. The argument from SSP to extensionality relied on parthood being a partial order. In particular, it relied on a crucial use of the antisymmetry axiom.

Antisymmetry If $x$ is part of $y$ and $y$ part of $x$, then $x$ and $y$ are identical.

Antisymmetry, too, has been treated with all undue respect. Simons (1987) writes regarding the partial order axioms,

These principles are partly constitutive of the meaning of 'part', which means that anyone who seriously disagrees with them has failed to understand the word.

To be sure, it does seem odd to think that two distinct things might be parts of each other, but inconceivable?. Antisymmetry is an immediate consequence of the asymmetry of proper

\footnotetext{
${ }^{17}$ Moreover, the historical motivations for mereology seem predicated on these type of structures being explicitly ruled out. Witness Goodman,

The platonist may distinguish these entities by venturing into a new dimension of Pure Form, but the nominalist recognizes no distinction of entities without a distinction of content. ((1951), 26)
} 
parthood - namely, if $x$ is a proper part of $y$, then $y$ is not a proper part of $x$ - and the definition of parthood as the disjunction of proper parthood and identity. But matters here might not be so straightforward; as there are other definitions of parthood that might be better motivated in the current context. ${ }^{18}$ What reasons are there for rejecting antisymmetry to avoid extensionality? Well, first of all, there is a very natural sense in which antisymmetry is an extensionality principle for improper parthood. Recall that extensionality principles all assert that if objects have the relevant mereological relations to all the same objects, then they are identical. Antisymmetry is no exception here; the relevant mereological relation is improper parthood. Thus, antisymmetry says if two objects have the same improper parts, they are identical. Given the similarity of antisymmetry to other extensionality principles, it might appear ad hoc to reject the others but hold on tightly here.

A second reason for rejecting antisymmetry is that it allows one to accept supplementation principles in their full strength. That is, rejecting antisymmetry is sufficient for avoiding extensionality principles of all stripes, even in the presence of SSP and unrestricted fusion. ${ }^{19}$ Of course, accepting SSP is not without consequence; it requires the acceptance of the following principle: ${ }^{20}$

Proper Parts Principle (PPP) For composites $x$ and $y$, if every proper part of $x$ is a proper part of $y$, then $x$ is part of $y$.

Simons suggests PPP as the culprit behind extensionality, saying that "the extensional aspect of extensional mereology appears to be closely connected with PPP" ( (1987), 28). On the contrary, however, one can easily accept PPP without being an extensionalist. More-

\footnotetext{
${ }^{18}$ See Cotnoir (2010) and Parsons (n.d.) for further discussion.

${ }^{19}$ See Cotnoir (2010) for proofs.

${ }^{20}$ Much like SSP is one half of the extensionality of overlap, PPP is essentially one direction of the extensionality of proper parthood.
} 
over, PPP is exceedingly natural. Since it would appear that $y$ 's inclusion of all the proper parts of $x$ should be sufficient for $x$ s being included in $y$ as well.

The naturalness of PPP comes to fore when considering the following oddity forced on the anti-extensionalist who rejects supplementation principles but accepts antisymmetry: they are forced to conclude that the clay that makes up the statue is not part of the statue! Why? Well, in order for the statue and clay to be distinct, they cannot be parts of each other; and in order for the statue and clay to be a counterexample to extensionality, they must have the same proper parts.

By contrast, the anti-antisymmetry mereologist can easily accept that the clay is part of the statue. And thus PPP provides the reason: since every proper part of the clay is a proper part of the statue, the clay is part of the statue. And moreover, symmetrical reasoning ensures that the statue is part of the clay. Thus the clay and the statue are parts of each other. But since we are supposing that they are not identical, they must be distinct mutual proper parts. This is Thomson's view when she suggests that the statue is constituted by the clay, and that constitution requires mutual parthood: " $x$ constitutes $y$ at $t$ only if $x$ is part of $y$ at $t$ and $y$ is part of $x$ at $t^{\prime \prime}((1998), 155)$. But constitution, Thomson thinks, does not imply identity. ${ }^{21}$ One might of course think it odd to have the statue be part of the clay. But I submit that this is mostly due to the nature of the example, and the fact that we tend to think of the statue as being grounded or dependent on the clay in an asymmetric way. Taking the example of the lego house and boat, the mutual parthood view feels natural enough.

In fact, PPP and principles like it were originally said to be definitional for the notion of parthood. For Leonard and Goodman's (1940) axiomatization of CEM, the extensionality of overlap is simply equivalent to antisymmetry. Parthood is defined via overlap thus: $x$ is part

\footnotetext{
${ }^{21}$ See Thomson (1983) p. 208 and p. 219 footnote 12.
} 
of $y$ iff everything that overlaps $x$ also overlaps $y$. Thus, if objects overlap the same things, they must be mutual parts by definition. Hence, antisymmetry yields extensionality.

A third reason for favoring non-antisymmetric mereology over its unsupplemented cousin comes from thinking about locations. What is the relation between an object's location, and the location of its parts? The answer, it turns out, is surprisingly complicated. ${ }^{22}$ However, one principle, which I'll call 'Inclusion', seems very natural:

Inclusion If the location of $x$ is a subregion of the location of $y$, then $x$ is part of $y$.

There is a natural attraction to the idea that the structure of locations should be in harmony with the structure of parts. Inclusion is compelling, I think, because it represents one way in which these structures may be in harmony. But notably, the unsupplemented antiextensionalist cannot accept the inclusion principle. Why? Well, if two distinct objects are co-located, then inclusion tells us they must be mutual parts, and hence by antisymmetry they must be identical. By contrast, the anti-antisymmetry anti-extensionalist can accept the inclusion constraint; and that is a mark in its favor.

A natural application of this thought involves entangled quantum particles; such things are typically thought to be co-located. ${ }^{23}$ Supposing such particles were mereological simple (i.e. had no further proper parts), the unsupplemented anti-extensionalist cannot explain their co-location in mereological terms - that is, they cannot distinguish two entangled particles from two non-entangled particles. The mutual parts theorist, however, has something more to say: the two entangled simples are mutual parts by virtue of being co-located,

\footnotetext{
${ }^{22}$ For a taste of the complexities involved, see Uzquiano (2011).

${ }^{23}$ Some have argued that, given the Indistinguishability Hypothesis of quantum mechanics, entangled particles are qualitatively indiscernible and yet distinct. French and Redhead (1988) argue that this includes indiscernibility with respect to their relational properties, and more specifically their locations. For more on putative counterexamples to the Identity of Indiscernibles (including quantum cases), see Hawley (2009).
} 
whereas two non-entangled simples bear no parthood relations to each other at all. ${ }^{24}$

So much for extensionality, which we have seen can motivate the rejection of either supplementation or antisymmetry. Setting aside reasons to do with extensionality, the rejection of antisymmetry has received additional independent support from philosophers who have put forth a number of counterexamples to it. The first such counterexample is due to Sanford (1993), who cites Borges' 'Aleph' as an example: “I saw the Aleph from all points. I saw the earth in the Aleph and in the earth the Aleph once more and the earth in the Aleph [...]". As Sandford notes, the Aleph is intended to have everything as a part, including the earth. But apparently the Aleph is a proper part of the earth, given the fact that it is sitting on the stairs in Beatriz Viterbo's house. van Inwagen (1993) has responded (and Varzi(1999, 2006a) concurs) that examples intended as fictional do not constitute counterevidence to conceptual truths; counterexamples to antisymmetry remain, for van Inwagen and Varzi, inconceivable.

A structurally similar example from non-fiction was recently put forward by Tillman and Fowler (2012).

Suppose that the universe exists. The universe is intended here in the most inclusive sense: a thing such that absolutely everything is a part of it. It's helpful to have a name for it. Assuming there is a unique such thing, let's name it $U$. According to a popular view of semantic content, 'U exists' semantically encodes a singular, structured proposition that has $U$ itself as a constituent as well as the property of existing. By hypothesis, this proposition is a proper part of $U$. But $U$ is in turn a proper part of the relevant proposition.

\footnotetext{
${ }^{24}$ This point is made by Parsons (n.d.). Of course, there is an interesting debate as to whether two simples can be co-located. See Hawthorne (2006) for discussion.
} 
Since $U$ is part of the proposition, and the proposition is part of $U$, Tillman and Fowler take this a evidence that parthood must fail to be antisymmetric. Of course this relies on a few crucial assumptions, not least of which are: (i) that sentences express propositions, and (ii) that constituents of propositions are parts.

It is worth highlighting that problems for the antisymmetry principle needn't involve a fusion of everything. For example, suppose propositions are expressed by sentences (1) and (2) below. ${ }^{25}$

(1) The proposition expressed by (2) is true.

(2) The proposition expressed by (1) is contingent.

It would appear that the proposition expressed by (1) is a constituent of - and hence part of - the proposition expressed by (2), and vice versa. Hence, since the two propositions are distinct, they must be mutual parts. ${ }^{26}$

More examples involving parthood loops are given in Cotnoir and Bacon (2012). But whatever one thinks of these examples, it is clear that CEM postulates other strong connections between parthood and identity. A further objectionable connection between parthood and the identity of sums in CEM is our topic for the next section.

\section{THE PARTS JUST ONCE PRINCIPLE \& IDEMPOTENCY}

What is the difference between the words 'stared' and 'starred'? They obviously express different concepts: one is what I often do blankly off into space, sitting at my desk; the other

\footnotetext{
${ }^{25}$ Indeed, the existence of such propositions is a central component to the solution of the liar paradox defended by Barwise and Etchemendy in (1987).

${ }^{26}$ For another solution to these puzzles like these, see Gilmore (forthcominga).
} 
is what movie actors do in films. But orthographically, they are composed of different letters - well 'different' in one sense, but in another sense the same.

Mereological composition (or summation) in CEM has another feature that has caused some recent controversy. Let us call this feature the idempotence of composition.

Idempotence If $x$ is part of $y$, then the sum of $x$ and $y$ is identical to $y$.

I note that this is a slightly different formulation from the more usual property called 'idempotence': the sum of $x$ with itself is just $x$; that is, taking the sum of something-twice-over gives you no more than taking the fusion of something-once-over. Of course, we have this in CEM as well. Given the reflexivity of (improper) parthood, we have it as an instance of the principle above. The more general formulation, however, fits the structure of our purported counterexamples more neatly.

Effingham and Robson (2007) discuss a related feature of CEM, called the 'Parts Just Once Principle'.

Parts Just Once Principle (PJO) For every composite $x, x$ cannot have $y$ as a part many times over.

Strictly speaking, PJO is not expressible in CEM due to the occurrence of 'many-times over'. The idempotence property, however, is expressible and a theorem of CEM. Both seem plausible as mereological principles. But recently authors have suggested that there are counterexamples.

It is important, however, to note that we should not misunderstand the 'many times over' in PJO as telling us that a composite $x$ cannot have distinct proper parts that are identical. That would be trivially true and immune to counterexamples. However, Effingham and Robson in their argument again PJO succumb to exactly this misunderstanding. 
For the Parts Just Once Principle to be false there could exist an $x$ that has $n$ proper parts, the $y$ s, (where $n>1$ ) such that the $y$ s are not the same proper part, but are the same object. If there is a whole which has two or more different proper parts, the whole has those proper parts by being part-related to two or more different (i.e. distinct) objects. So for each of the $y$ s, that $y$ is not identical to any of the other $y s$. Yet it is stipulated that the same object (call it $z$ ) is a part $n$ times over. So $z$ is identical to each of the $y s$ - and so by the transitivity of identity each of the $y$ s are identical to one another. A clear contradiction. ((2007), 635)

They assume that being part-related many-times-over is equivalent to being part-related to two or more distinct objects. But of course that assumption merely begs the question. No, what is required is for it to be possible that an object be part-related to another multiple times. Bennett explains,

Two people are cousins twice over, or 'double cousins', as they are called, just in case they are the children of pairs of siblings. Similarly, the being three feet from relation can hold multiple times between the same two entities: consider two antipodal points on a sphere, such that the shortest distance between them along the surface is three feet. But ...parthood?[...] I argue that [...] we can make sense of the idea of an entity's having a part twice - or four times - over. ((forthcoming), ???)

How can one make sense of such an idea? I will consider two possibilities: the first involves multi-location; the second involves the distinction between role and occupant.

Smith (2009) suggests the phenomenon of $x$ having a part $y$ many times over should be understood as having $x$ having a proper part $y$ that is multiply-located in many distinct sub- 
regions of the location of $x$. Endurantists are no strangers to the idea that an individual might be multiply located at different times. But could an object be multiply located in different regions at the same time?

Imagine Bob (the builder) would like to build a brick wall, but he only has one brick sitting in his basement. Luckily, Bob also has a time machine. So, at $t_{1}$, he takes his $t_{1}$-brick into the time machine, travels back to $t_{0}$, and places the $t_{1}$-brick next to the $t_{0}$-brick in his basement. So now he has two bricks - well, really he only has one brick, since the $t_{1}$-brick and the $t_{0}$-brick are numerically identical, but multiply located. Bob travels back to $t_{1}$ and does this a hundred more times. After he's finished time-traveling, he uses his multiply located brick to build a brick wall. ${ }^{27}$

The brick wall seems to be composed entirely of a single brick many times over. So it appears to be direct counterexample to PJO. Moreover, consider the brick wall just before I add the final (copy of the) brick - call this object, composed of the brick ninety-nine times over, Wall $_{99}$. Now, the brick is already part of Wall $_{99}$. According to idempotence, completing the wall by adding the final (copy of the) brick to Wall ${ }_{99}$ results in Wall ${ }_{99}$. But intuitively the result of adding the last brick should be Wall ${ }_{100}$. And Wall ${ }_{100}$ is not identical to Wall ${ }_{99}$ (since Wall $_{99}$ is a proper part of Wall $l_{100}$ and nothing is a proper part of itself). ${ }^{28}$ Thus, idempotence must fail.

Of course, there are a number of moves that defenders of PJO and idempotence could make in response to such a scenario. It does, after all involve time-travel which is known

\footnotetext{
${ }^{27}$ Examples such as this first appeared in Effingham and Robson (2007) and Gilmore (2007). See also Eagle's response (2010), and Gilmore's reply (2010). Likewise, see Smith's response (2009), and Effingham's reply (2010). Both discussions are addressing issues in the literature on persistence. Other interesting discussions that tackle the mereological implications of multi-location head-on are Donnelly (2010) and Kleinschmidt (2011).

${ }^{28}$ Of course, one might try to save idempotence by accepting that things can be proper parts of themselves. Indeed, the astute reader might have already considered this from previous thought experiments. See Cotnoir \& Bacon (2012) for a mereology in which this is possible.
} 
to raise difficulties. It's worth noting that the above example also violates WSP; thus, a host of philosophers must reject it as inconceivable. I leave any further discussion aside, since failures of PJO and idemoptence can be motivated without the appeal to time-travel.

A more straightforward (and widely accepted) example of multi-location involves universals. Universals are typically said to be 'wholly located wherever they are instantiated'. Some have thought that universals can have other universals as parts; the locus classicus being Armstrong (1986).

As water is $\mathrm{H}_{2} \mathrm{O}$, the structural universal WATER has the universal HYDROGEN as a component twice over, and the universal OXYGEN as a component once over (and perhaps we'd like to include two copies of the BoNDING universal). By contrast, hydrogen peroxide is $\mathrm{H}_{2} \mathrm{O}_{2}$. Hence, the structural universal HYDROGEN PEROXIDE has the component HYDROGEN twice over, and the component OXYGEN twice over (plus, perhaps, BONDING thrice over).

Summing together WATER with an extra OXYGEN (and, if we include BONDING, an extra instance of that too) does not yield WATER as idempotence would predict, but yields HYDROGEN PEROXIDE. Hence, either OXYGEN is not part of WATER, or idempotence fails. So, if structural universals were structured by CEM, then WATER and HYDROGEN PEROXIDE would be identical. But they aren't.

Lewis (1986) concludes, pace Armstrong, that structural universals do not exist since they cannot be handled within CEM. And for Lewis, it is either (classical extensional) mereology or 'magic'. Bennett (forthcoming) suggests an alternate account, however, one which allows one to keep a mereological account of structural universals whilst rejecting idempotence. $^{29}$

Bennett's mereology makes use of the distinction between a role and an occupant of that

\footnotetext{
${ }^{29}$ For distinct mereological proposals, see Bader (forthcoming) and Mormann (2010). For detailed arguments as to why Lewis's mereology of 'magic' is a false dichotomy, see Hawley (2010).
} 
role; this allows for the distinction between two types of objects in our domain: 'parthood slots', and the 'fillers' which fill those slots. Once it is allowed that objects have this slot structure, it is a small step toward allowing that a single part might fill more than one slot in the same object. A structural universal like WATER, for example, has three (perhaps five) slots, two of which are filled by HYDROGEN and one of which is filled by OXYGEN (and perhaps two slots filled by BONDING).

Unfortunately, Bennett's mereology runs into some trouble with mereological sums. She does not propose any kind of mereological sum or fusion operation on parts. Slots cannot be parts of slots; nor are they parts of the objects they are slots for. As a result, it is very difficult to tell when looking at some parts $a$ and $b$ what their sum should be. We need to know what slot-structure is present in the whole before we can determine what the relevant sum is. How many slots need to be filled? There are many possible answers to this question, each of which determines at least one distinct object, usually many more. Suppose, for example, the whole has three slots. Then there are six possible sums aab, $a b a, b a a, a b b, b a b$, and $b b a$, assuming it matters to the identity of the object which part fills which slot. Even if we identify objects like $a b a$ and $b a a$, we still fail to have it that mereological sum is unique (i.e. the extensionality of sums fails). Perhaps this is to be expected. However, given the complexities of composition, Bennett does not develop any theory of it. These are open questions a fully developed non-idempotent mereology would need to answer. ${ }^{30}$

\footnotetext{
${ }^{30}$ There are potential answers available; it's not as if any such theory will inevitably run into trouble. I plan to address these in future work.
} 


\section{CONCLUSION}

Recent discussions in the literature on mereology have consistently attempted to push the boundaries of the kinds metaphysical structures we might have previously thought possible. Those who hold most tightly to principles like WSP, antisymmetry and PPP as analytic are forced to regard this battery of counterexamples as inconceivable. ${ }^{31}$ However, mereologies which deny such principles seem to be capable of doing quite a bit of metaphysical work. Resolving the puzzles of material constitution, providing a mereological account of coincidence, and explaining the structure behind structural universals - these are just some of the theoretical applications that have opened up. Of course, some of these applications are stranger than others. The more sane among us will likely wish to pick and choose. But the world of non-classical mereologies is just beginning to be seen in formal detail. Rival systems are still to be developed. The costs and benefits are still to be weighed. Perhaps this is work in which you, the reader, would like to take part. ${ }^{32}$

\section{References}

Armstrong, D. M. (1986), 'In defense of structural universals', Australasian Journal of Philosophy 64, 85-88.

Bader, R. (forthcoming), Multiple-domain supervenience for non-classical mereologies, in 'Ontological Dependence and Supervenience', Philosophia.

\footnotetext{
${ }^{31}$ At this point, it might be within one's rights to complain to such analyticity-mongerers, "You keep using that word. I do not think it means what you think it means."

${ }^{32}$ Thanks to the Metaphysics Reading Group at the University of St Andrews for detailed comments and advice - in particular to Katherine Hawley, Ulrich Meyer, and Bruno Jacinto, Martin Lipman, Andrew Peet, Caroline Touborg, and Michael Traynor. Thanks also to Ross Cameron and an anonymous referee for suggesting improvements to the paper.
} 
Barwise, J. \& Etchemendy, J. (1987), The Liar, Oxford University Press.

Bennett, K. (forthcoming), 'Having a part twice over', Australasian Journal of Philosophy .

Bohn, E. (2009), 'An argument against the necessity of unrestricted composition', Analysis 69(1), 27-31.

Burkhardt, H. \& Dufour, C. (1991), Part/whole I: History, in H. Burkhardt \& B. Smith, eds, 'Handbook of Metaphysics and Ontology', Philosophia, Munich, pp. 663-673.

Caplan, B., Tillman, C. \& Reeder, P. (2010), 'Parts of singletons', Journal of Philosophy 107, 501533.

Casati, R. \& Varzi, A. C. (1999), Parts and Places: The Structures of Spatial Representation, MIT Press, Cambridge (MA).

Cotnoir, A. J. (2010), 'Anti-symmetry and non-extensional mereology', The Philosophical Quarterly 60(239), 396-405.

Cotnoir, A. J. \& Bacon, A. (2012), 'Non-wellfounded mereology', Review of Symbolic Logic 5(2), 187-204.

Donnelly, M. (2010), Parthood and multi-location, in D. Zimmerman, ed., 'Oxford Studies in Metaphysics', Vol. 5, Oxford University Press, pp. 203-243.

Donnelly, M. (2011), 'Using mereological principles to support metaphysics', Philosophical Quarterly 61, 225-246.

Eagle, A. (2010), Location and perdurance, in D. Zimmerman, ed., 'Oxford Studies in Metaphysics', Vol. 5, Oxford University Press, pp. 53-94. 
Eberle, R. (1970), Nominalistic Systems, Kluwer.

Effingham, N. (2010), 'Mereological explanation and time travel', Australasian Journal of Philosophy 88(2), 333-345. forthcoming.

Effingham, N. \& Robson, J. (2007), 'A mereological challenge to endurantism', Australasian Journal of Philosophy 85, 633-640.

Fine, K. (1999), 'Things and their parts', Midwest Studies in Philosophy XXIII, 61-74.

Fine, K. (2003), 'The non-identity of a material thing and its matter', Mind 112, 195-234.

Fine, K. (2010), 'Towards a theory of part', Journal of Philosophy 107(11), 559-589.

Forrest, P. (2002), 'Non-classical mereology and its application to sets', Notre Dame Journal of Formal Logic 43, 79-94.

French, S. \& Redhead, M. (1988), 'Quantum physics and the identity of indiscernibles', British Journal for the Philosophy of Science 39, 233-246.

Geach, P. T. (1962), Reference and Generality, Cornell University Press.

Gilmore, C. (2007), Time travel, coinciding objects, and persistence, in D. Zimmerman, ed., 'Oxford Studies in Metaphysics', Vol. 3, Oxford University Press, pp. 177-198.

Gilmore, C. (2010), Coinciding objects and duration properties: Reply to Eagle, in D. Zimmerman, ed., 'Oxford Studies in Metaphysics', Vol. 5, Oxford University Press, pp. 95-111.

Gilmore, C. (forthcominga), Parts of propositions, in S. Kleinschmidt, ed., 'Mereology and Location', Oxford University Press. 
Gilmore, C. (forthcomingb), Quasi-supplementation, plenitudinous coincidentalism, and gunk, in 'Substance: New Essays', Philosophia Verlag.

Goodman, N. (1951), The Structure of Appearance, Harvard University Press, Cambridge, MA.

Hawley, K. (2009), 'Identity and indiscernibility', Mind 118(1), 101-119.

Hawley, K. (2010), 'Mereology, modality, and magic', Australasian Journal of Philosophy 88(1), 117-133.

Hawthorne, J. (2006), 'Three Dimensionalism’, Metaphysical Essays pp. 85-111.

Hovda, P. (2009), 'What is classical mereology?', Journal of Philosophical Logic 38(1), 55-82.

Johnston, M. (2006), 'Hylomorphism', Journal of Philosophy CIII, 614-630.

Kleinschmidt, S. (2011), 'Multilocation and mereology', Philosophical Perspectives 25, 253-276.

Koslicki, K. (2008), The Structure of Objects, Oxford University Press.

Leonard, H. S. \& Goodman, N. (1940), 'The calculus of individuals and its uses', Journal of Symbolic Logic 5, 45-55.

Leśniewski, S. (1916), Foundations of the general theory of sets i, in D. B. F. R. S.J. Surma, J.T. Srzednicki, ed., 'Collected Works', Kluwer. Trans. published (1992).

Lewis, D. (1986), 'Against structural universals', Australasian Journal of Philosophy 64, 25-46.

McDaniel, K. (2009), 'Structure-making', Australasian Journal of Philosophy 87(2), 251-274.

McDaniel, K. (2010), 'Parts and wholes', Philosophy Compass 5, 412-425. 
Mormann, T. (2010), 'Structural universals as structural parts: Towards a general theory of parthood and composition', Axiomathes 20, 229-253.

Niebergall, K. (2011), Mereology, in 'Continuum Companion to Philosophical Logic', Continuum.

Parsons, J. (n.d.), An extensionalist's guide to non-extensional mereology. ms.

Paul, L. (2006), 'Coincidence as overlap', Noûs 40(4), 623-659.

Paul, L. (2010), 'The puzzles of material constitution', Philosophy Compass 5, 579-590.

Pontow, C. \& Schubert, R. (2006), 'A mathematical analysis of theories of parthood', Data and Knowledge Engineering 59, 107-138.

Rea, M. (2010), 'Universalism and extensionalism: a reply to Varzi', Analysis 70(3), 490-496.

Rossberg, M. (2009), Leonard, Goodman, and the development of the calculus of individuals, in G. E. et al., ed., 'From Logic to Art: Themes from Nelson Goodman', Ontos, Frankfurt, pp. 51-69.

Russell, J. (2008), The structure of gunk: Adventures in the ontology of space, in D. Zimmerman, ed., 'Oxford Studies in Metaphysics', Vol. 4, Oxford University Press, pp. 248-278.

Sanford, D. (1993), 'The problem of the many, many composition questions, and naïve mereology', Noûs 27(2), 219-228.

Sider, T. (2003), Four-dimensionalism: An ontology of persistence and time, Oxford University Press.

Simons, P. M. (1987), Parts: A Study In Ontology, Clarendon, Oxford. 
Simons, P. M. (1991), Free part-whole theory, in K. Lambert, ed., 'Philosophical Applications of Free Logic', Oxford University Press, Oxford, pp. 285-306.

Smith, D. (2009), 'Mereology without weak supplementation', Australasian Journal of Philosophy 87, 505-511.

Smith, N. J. (2005), 'A plea for things that are not quite all there: Or, is there a problem about vague composition and vague existence?', Journal of Philosophy 102, 381-421.

Tarski, A. (1929), Foundations of the geometry of solids, in J. Corcoran, ed., 'Logic, Semantics, Metamathematics', Hackett, pp. 24-29. Trans. published (1956).

Thomson, J. J. (1983), 'Parthood and identity across time', Journal of Philosophy 80(4), 201-220.

Thomson, J. J. (1998), 'The statue and the clay', Noûs 32(2), 149-173.

Tillman, C. \& Fowler, G. (2012), 'Propositions and parthood: The universe and antisymmetry', Australasian Journal of Philosophy 90, 525-539.

Uzquiano, G. (2011), Mereological harmony, in D. Zimmerman \& K. Bennett, eds, 'Oxford Studies in Metaphysics', Vol. 6, Oxford University Press, pp. 199-224.

van Inwagen, P. (1987), When are objects parts?, in 'Philosophical Perspectives', Vol. 1.

van Inwagen, P. (1993), 'Naïve mereology, admissible valuations, and other matters', Noûs $27(2), 229-234$.

Varzi, A. (2006a), Mereology, in E. N. Zalta, ed., 'The Stanford Encyclopedia of Philosophy'. URL: http://plato.stanford.edu/archives/win2006/entries/mereology/

Varzi, A. (2006b), 'A note on the transitivity of parthood', Applied Ontology 1, 141-146. 
Varzi, A. (2008), 'The extensionality of parthood and composition', The Philosophical Quarterly 58, 108-133.

Varzi, A. (2009), 'Universalism entails extensionalism', Analysis 69, 599-604.

Weber, Z. \& Cotnoir, A. J. (n.d.), Inconsistent boundaries. ms.

Wiggins, D. (1968), 'On being at the same place at the same time', Philosophical Review 77, 9095. 